\title{
Determinants of Immunization Coverage and Associated Factors among Children aged under Two-Year-Old in the National Immunization Program of Mewat district, Haryana (2019-2020)
}

\author{
Vishesh Kumar \\ Doctor of Medicine, Texila American University, India
}

\begin{abstract}
Background: Vaccination against childhood communicable diseases through Expanded Program on Immunization is one of the most cost-effective public health interventions. Additional 1.5 million child deaths can be prevented if global vaccination coverage is improved. Mewat district has one of India's lowest immunization rates despite a long-standing Universal Immunization Program and continues to sustain a high prevalence of vaccine-preventable diseases. This study investigates determinants of immunization status among children aged 0-23 months. Methods: A community-based cross-sectional study was conducted from December 2019 to June 2020, among 800 children aged 023 months, randomly selected in one rural and one urban ward each from all 4 blocks of Mewat. Socio-demographic conditions and vaccine-related data were collected using a semi-structured questionnaire. Immunization was assessed by vaccination card and by mother's recall where the card was unavailable. Results:Mewat has increased full immunization coverage from 13.1\% in 2015-16 to 59.4\%. Immunization card was available with 68.5\% (292/426) beneficiaries. Dropout rates for Pentavalent1 to Pentavalent 3 was $27.5 \%$ and $54 \%$ for Bacillus Calmette-Guerin to measles. After adjusting for the state of residence, religion, gender, paternal education, health professional presence during birth, place of vaccination and knowledge of mother on due dose were significantly associated with full immunization. Awareness gap and fear of side effects for vaccines were main reasons of vaccine hesitancy. Conclusion: Full immunization coverage in the district is sub optimal and behind the desired coverage goal, mainly due to vaccine hesitancy. Enhancing community knowledge about the benefits of vaccination is recommended.
\end{abstract}

Keywords: Below two years children, immunization, reasons for partial immunization, drop out, full immunization.

\section{Introduction}

Vaccination against childhood communicable diseases through the Expanded Programme on immunization (EPI) is one of the most cost-effective public health interventions. Vaccination contributes substantially to the achievement of Sustainable Development Goals (SDGs) by reducing mortality and morbidity among children. Globally around $29 \%$ of under-five deaths were due to vaccine-preventable diseases (VPD) in 2017 as estimated by the United Nations interagency group for child mortality estimation [1]. India accounted for the highest number of under-five deaths globally in 2015 [2]. Routine immunization is the nation's strategic investment and an essential strategy for saving lives and protecting health of population.
The Global Vaccine Action Plan 2011-2020 (GVAP) was unanimously endorsed in 2012 by the World Health Assembly (WHA). Globally, 19.7 million children and $70 \%$ of whom were zero-dose children still remain unvaccinated with basic childhood vaccines in 2018 [3]. GVAP had put a goal to reach immunization coverage of at least $90 \%$ children in each nation and $80 \%$ in every district by 2020 . GVAP goals could potentially avert 25 million vaccinepreventable deaths by the end of the 2020 [4, 5].

India launched the Expanded Program on Immunization in 1978 and converted to the Universal Immunization Program (UIP) in 1985. It is one of the world's largest programs and currently catering to an annual cohort of 26.7 million infants and 30 million pregnant women. An estimated $38 \%$ of children still 
failed to receive all essential vaccines in their first year of life in 2016 in the country [6]. The Ministry of Health and Family Welfare Government of India launched Mission Indradhanush in December 2014 and Intensified Mission Indradhanush (IMI) in October 2017 with an aim to vaccinate all children under 2 years of age [7, 8].

Various national immunization surveys conducted from time to time had shown suboptimal vaccination coverage in Mewat district. The coverage had always been historically low as compared to the other districts of Haryana State. District Level Household and Facility Surveys-3 (DLHS-3) conducted in 2007-08 had $11.0 \%$ full vaccination (rural 9.6\%) and DLHS4 in 2012-13 had 27.3\% full vaccination (rural 20.8\%) [9]. National Family Health Survey-4 (NFHS-4) in 2015-16 had shown $13.1 \%$ full vaccination in Mewat (rural 11\%) [10].

Mewat district had been targeted for immunization intensification activities since December 2014 through Mission Indradhanush and Intensified Mission Indradhanush by the federal government with the goal of improving full vaccination to $90 \%$ within 5 years. To measure the impact of these immunization intensification campaigns, the Coverage Evaluation Survey (CES) was conducted by a government of India in 2018. This survey had shown that $22.5 \%$ of children did not receive any vaccine and full immunization coverage was $40.8 \%$ in Mewat [11]. Government of India had prepared a road map for achieving $90 \%$ full immunization coverage across the country in 2019 [12]. It is well recognized that national, state and district level immunization averages mask inequities in coverage, knowledge of which is essential to devise corrective strategies at the sub-districts level.

Mewat is one of the most socioeconomically backward district and mainly inhabited by Meo Muslims. They constitute $79.2 \%$ of the total population as per 2011 census. A high birth rate characterizes the district; most families have more than three to four living children in the study population. The proportion of beneficiaries for vaccination services were relatively higher, with infants and children below six years constituting $22.78 \%$ of the total population [13]. The majority $(89 \%)$ of the population is living in rural areas. The lack of literacy, public transport, inadequate health facilities, and a chronic shortage of potable water add immense difficulty to the masses and in particularly to the lives of ordinary women in Mewat [14]. The district had reported multiple diphtheria and measles outbreaks in 2018-19 as per the WHO-National Public Health Surveillance (NPSP) data. Mewat's large incompletely immunized susceptible cohort translates into increased risk for vaccinepreventable diseases, which partially explains the continued high burden of morbidity and mortality from such infections in children of this district. We assessed the routine immunization coverage in children below two years to determine the reasons for incomplete immunization in to identify areas for improvement.

\section{Materials and Methods}

\section{Study Area}

The study was conducted in urban and rura area of district Mewat (Haryana). Study design: It was community based cross-sectional study.

\section{Study Period}

Study was conducted from December 2019 to May 2020. Study population: The study included children aged between 0-23 months whose parents resided in the area for the last two years.

\section{Inclusion criteria}

1. Children aged between 0-23 completed months at time of study.

2. Children in the age group of 0-23 months whose parents were residing in the study area for a period of not less than two years.

3. Mothers/ Caregivers/Guardians who gave the consent for participation.

\section{Exclusion criteria}

1. Children in the age group of 0-23 months whose parents were residing in the study area for less than two years.

2. Parents who were not willing to participate in the study.

A community-based cross-sectional study was conducted from December 2019 to May 2020 in Mewat district. The study was conducted in all four blocks (Nuh, Ferozepur Jhirka, Punhana, and Taoru). A mixed-method design was adopted for the assessment, which was conducted in two stages. A complete list of 
villages in rural areas and wards in the Mewat district's urban areas was procured from the census department. From this sampling frame, randomly one rural and one urban ward areas were selected from each block.

\section{Sample Size Calculation for Quantitative Data Collection}

The sample size was calculated based on the proportion of partial and unimmunized children in Mewat from the latest available information of Intensified Mission Indradhanush-Coverage Evaluation Survey, 2018. The sample size was calculated using the following formula [15]:

$$
\mathrm{N}=[\operatorname{De} \times \mathrm{Z} 2 \times \mathrm{p}(1-\mathrm{p})] / \mathrm{d} 2
$$

Where $\mathrm{N}$ is the sample size, De (2) is the design effect, the ratio between the variance from the cluster design to the variance that was obtained from a simple random sampling, $\mathrm{Z}$ (1.96) is the certainty wanted to be expressed in the percentage point of the normal distribution corresponding to the 2-sided level of significant, $P(\sim 41 \%)$ is the immunization coverage of Mewat and d (5\%) is the desired width of the confidence interval.

Therefore,

$$
\mathrm{N}=\left[2 \times(1.96)^{2} \times 0.41 \times 0.59\right] /(0.05) 2=742 \text {. }
$$

A non-response rate of $8 \%$ was added for a total sample size of 800 .

In the second stage, households were surveyed for quantitative data collection. A simple random sampling (using the revolving pen technique) was used to select the first household for the survey in each selected village or ward. Every household with a child below two years was selected until the desired number of children were met from each selected village and urban ward. Information regarding 0-23 months children was recorded from selected households using an ODK tool, an Android-based tool. Mother/caregiver having at least one child aged 0-23 months were included, while those children whose mothers/caregivers were found to be mentally/critically ill during the data collection period were excluded from the study.

\section{Data Processing and Analysis}

For quantitative data collection, a structured questionnaire was administered to the key respondents. The questionnaire was designed on an android based ODK tool. The questionnaire mainly included immunization histories of children, mothers' sociodemographic characteristics, and knowledge of mothers on immunization. Information on vaccination coverage was collected in two ways: from the maternal and child protection (MCP) card or from the mother's/caregiver's verbal report. Data from MCP card was extracted in cases where a child immunization card was available. When there was no vaccination card for the child or if a vaccine had not been recorded on the card as being given, the mothers were asked to recall the specific vaccines given to their children. The information obtained from the child's card was taken when both conditions have been met. Before starting the actual data collection, the questionnaire was pretested on 5\% of similar respondents in a similar locality of adjoining Gurugram district, which was not included in the final study. All field staff and the principal investigator have assessed the clarity and completeness, consistency, accuracy of the data. The data were cleaned and entered EpiInfo 7 for further analysis.

An excel-based and EPI -Info 7 calculations worksheet was prepared for the analysis. Bivariate and multivariate logistic regression analyses were conducted along with adjusted Odds Ratios. In the bivariable analysis, independent variables significantly associated with the dependent variable at $\mathrm{p}$-value $<0.20$ were included in the multivariable logistic regression analysis. The variables significantly associated at $\mathrm{p}$-value $<0.05$ were identified as predictors of immunization status. The degree of association was also assessed using crude and adjusted odds ratios.

\section{Determinants of Immunization Status}

Eight household determinants were taken into consideration, including the residence type (urban or rural), presence of a professional

attendant during childbirth (institutional delivery or home delivery), mother's 
employment status, parental education, number of living children or parity status, decisionmaker for immunization in the family, wealth status and household income. The residence type was categorized into rural and urban areas. The presence of a professional birth attendant during childbirth was defined as either the birth was attended by an auxiliary nurse-midwife or attended by a health professional (physician or trained nurse). Educational levels of parents were defined as no education, primary and higher than primary. Mothers' employment status was categorized as unemployed or employed. Parity status was considered low if the family had one to three children and high if the family had four or more than a four number of living children. Distance to a health facility or immunization session site was convenient if less than 30 minutes' walk to the session site.

\section{Ethical Considerations}

To maintain regular protocols of ethics, informed verbal consent was obtained from the respondents, and no attempt was made to capture the interviewees' identities.

\section{Definitions}

The immunization status of the children were categorized as follows:

\section{Fully Immunized}

Fully immunized child was defined as a child who had received one dose of Bacillus Calmette-Guerin (BCG), 3 doses of Diphtheria, Pertussis, Tetanus (DPT)/Pentavalent vaccine and 3 doses of Oral Polio Vaccine and one dose of Measles Containing Vaccine (MCV) within the age of one year as per national immunization schedule.

\section{Partial Immunization}

A child who has received at least one of the vaccines but has not completed the entire set of vaccines as per the national immunization schedule.

\section{Not Immunized}

When a child who has not received any vaccine as per the universal immunization programme schedule.

\section{Not fully Immunized}

A combination of both partially immunized and not immunized. Pentavalent vaccine: This is a combination of Diphtheria, Pertussis, Tetanus, Haemophilus Influenza type B and hepatitis B antigens.

\section{Delayed Vaccination}

Delayed vaccination for each vaccine was defined as administering the vaccine dose after 28 days of the minimum recommended age, as per India's national immunization schedule.

\section{Distance to Health Facility (in walk time)}

Distance to a health facility or immunization session site, if $<30$ minutes, was taken as session site convenient for vaccination.

A pre-designed survey questionnaire was used to assess the reasons for nonimmunization and partial immunization of the selected child aged below 2 years.

\section{Results}

Eight hundred children aged 0-23 months were included in the study. A mean and standard deviation $( \pm \mathrm{SD})$ of mothers' age was $24.1( \pm 3.3)$ years. The mean age of the child was $11.1( \pm 6.5)$ months, and $48.4 \%$ of them were females. Half 388 (48.5\%) of the mothers were not able to read and write, while only $7.3 \%$ of them attained a secondary or higher level of education. Nearly one-half 390 (48.8\%) of the father were also uneducated. About 427 (53.4\%) respondents were Muslims, while 373 (46.6\%) were Hindus. About two-thirds 595 $(74.4 \%)$ of the total children belonged to other backward classes (OBCs) and mainly were Muslim OBCs (53.3\%). About 123 (15.4\%) belonged to the scheduled caste (SC), $8(1 \%)$ to the scheduled tribe (ST), and $74(9.3 \%)$ to the non-SC/ST/OBC category.

Most children, 690 (86.3\%), were born in public or private institutions, while $110(13.8 \%)$ were home delivered. Around 203 (25.4\%) of the children included in the study were of birth order four and above, reflecting a bigger family size in the sample. A few more than a quarter, $224(28 \%)$ were of the first order. The children of second and third order were $216(27 \%)$ and 157 (19.6\%). More than one-fourth 206 (26.4\%) of the households had four or more living children. About 353 (44.2\%) of the households had an average monthly income below 10,000 rupees per month (Below Poverty Line limit). More than one-third $(36.4 \%)$ of caregivers were agricultural laborers and 
$353(44.1 \%)$ were of low economic status. (Table1 and Table 2).

Figure 1 and 2 shows immunization coverage in Haryana and Mewat in various national immunization surveys. Immunization status of the total included children $(\mathrm{N}=800)$, $426(53.25 \%)$ of them were fully immunized as per age, $345(43.13 \%)$ were partially vaccinated, and the rest $29(3.63 \%)$ had not received any antigen. Out of 426 fully vaccinated children, 292 (68.5\%) had evidence of immunization supported by the card, while the vaccination status of 134 (31.5\%) children was determined by mothers to recall. Similarly, 173 (50.1\%) were confirmed as partially immunized by card, while $172(49.9 \%)$ were based on mothers' recall. On the other hand, of the fully immunized children, 146 (18.25\%) had received timely vaccination, while 280 (35\%) received delayed vaccination. Table 3.

Turning to the individual types of immunization covered (Figure 3 and Figure 4) by the study, 769 (96.1\%) of children received BCG, $706(88.3 \%)$ of the children received both OPV1 and Pentavalent1, and 353 (44.1\%) received the measles-containing vaccine. Coverage rates declined for subsequent vaccine doses as $63.5 \%$ of children received OPV3, $63.9 \%$ Pentavalent 3 . The proportion of children who started certain vaccines but did not complete the next intended vaccine (dropout rate) was $28.4 \%$ for OPV1 to OPV3, 27.5\% was for Pentavalent1 to Pentavalent3, and 54\% for BCG to Measles containing vaccine.

Table 1. Socio-demographic and Economic Characteristics of Children aged 0-23 months in Mewat, Haryana 2019

\begin{tabular}{|c|c|c|c|c|}
\hline \multirow{2}{*}{ Characteristics } & \multicolumn{2}{|l|}{ Urban } & \multicolumn{2}{|l|}{ Rural } \\
\hline & Frequency $(\mathbf{N})$ & Percentage $(\%)$ & Frequency $(\mathbf{N})$ & Percentage (\%) \\
\hline \multicolumn{5}{|l|}{ Religion } \\
\hline Hindu & 234 & 58.5 & 139 & 34.8 \\
\hline Muslim & 166 & 41.5 & 261 & 65.3 \\
\hline \multicolumn{5}{|l|}{ Caste } \\
\hline Scheduled Caste & 92 & 23.0 & 31 & 7.8 \\
\hline Scheduled Tribe & 7 & 1.8 & 1 & 0.3 \\
\hline $\begin{array}{l}\text { Other Backward Caste } \\
\text { (OBC) }\end{array}$ & 269 & 67.3 & 326 & 81.5 \\
\hline General Caste & 32 & 8.0 & 42 & 10.5 \\
\hline \multicolumn{5}{|l|}{ MCP card } \\
\hline Yes & 260 & 65.0 & 208 & 52.0 \\
\hline No & 140 & 35.0 & 192 & 48.0 \\
\hline \multicolumn{5}{|l|}{ Gender } \\
\hline Male & 206 & 51.5 & 207 & 51.8 \\
\hline Female & 194 & 48.5 & 193 & 48.3 \\
\hline \multicolumn{5}{|l|}{ Place of delivery } \\
\hline Government & 205 & 51.3 & 208 & 52.0 \\
\hline Private & 155 & 38.8 & 122 & 30.5 \\
\hline Home & 40 & 10.0 & 70 & 17.5 \\
\hline \multicolumn{5}{|l|}{ Birth Order of the child } \\
\hline First & 113 & 28.3 & 111 & 27.8 \\
\hline Second & 120 & 30.0 & 96 & 24.0 \\
\hline Third & 83 & 20.8 & 74 & 18.5 \\
\hline Four and above & 84 & 21.0 & 119 & 29.8 \\
\hline \multicolumn{5}{|l|}{ Care provider } \\
\hline Mother & 359 & 89.8 & 364 & 91.0 \\
\hline Other Family members & 41 & 10.3 & 36 & 9.0 \\
\hline
\end{tabular}




\begin{tabular}{|c|c|c|c|c|}
\hline No schooling & 155 & 38.8 & 233 & 58.3 \\
\hline Primary & 84 & 21.0 & 63 & 15.8 \\
\hline Middle & 49 & 12.3 & 49 & 12.3 \\
\hline High/Secondary & 71 & 17.8 & 38 & 9.5 \\
\hline$\geq$ twelfth & 41 & 10.3 & 17 & 4.3 \\
\hline \multicolumn{5}{|l|}{ Father education } \\
\hline No schooling & 185 & 46.3 & 205 & 51.3 \\
\hline Primary & 33 & 8.3 & 30 & 7.5 \\
\hline Middle & 36 & 9.0 & 36 & 9.0 \\
\hline High/Secondary & 64 & 16.0 & 55 & 13.8 \\
\hline$\geq$ twelfth & 82 & 20.5 & 74 & 18.5 \\
\hline \multicolumn{5}{|c|}{ Employment of caregiver } \\
\hline Agriculture & 6 & 1.5 & 24 & 6.0 \\
\hline $\begin{array}{l}\text { Government/Private } \\
\text { job }\end{array}$ & 79 & 19.8 & 99 & 24.8 \\
\hline $\begin{array}{l}\text { Self-employed/Shop } \\
\text { keeper }\end{array}$ & 106 & 26.5 & 40 & 10.0 \\
\hline Daily wage laborer & 150 & 37.5 & 141 & 35.3 \\
\hline $\begin{array}{l}\text { Skilled labor } \\
\text { (mechanic/tailor/driver) }\end{array}$ & 59 & 14.8 & 96 & 24.0 \\
\hline \multicolumn{5}{|c|}{ Monthly income (Rupees) } \\
\hline BPL $(<10000)$ & 132 & 33.0 & 221 & 55.3 \\
\hline Middle (10000-25000 & 243 & 60.8 & 150 & 37.5 \\
\hline High $(>=25000$ & 25 & 6.3 & 29 & 7.3 \\
\hline \multicolumn{5}{|c|}{ Number of living children (Parity) } \\
\hline 1 & 113 & 28.3 & 113 & 28.3 \\
\hline 2 & 123 & 30.8 & 92 & 23.0 \\
\hline 3 & 79 & 19.8 & 71 & 17.8 \\
\hline$>4$ & 85 & 21.3 & 124 & 31.0 \\
\hline \multicolumn{5}{|l|}{ Type of Dwelling } \\
\hline Pucca & 388 & 97.0 & 332 & 83.0 \\
\hline Semi-Pucca & 12 & 3.0 & 36 & 9.0 \\
\hline Kutcha & 0 & 0.0 & 32 & 8.0 \\
\hline \multicolumn{5}{|c|}{ Source of fuel for cooking } \\
\hline Firewood / Dung cake & 14 & 3.5 & 305 & 76.0 \\
\hline LPG & 386 & 96.5 & 95 & 23.8 \\
\hline \multicolumn{5}{|l|}{ Place of vaccination } \\
\hline $\begin{array}{l}\text { Government Health } \\
\text { Facilities }\end{array}$ & 179 & 44.8 & 98 & 24.5 \\
\hline $\begin{array}{l}\text { Private Health } \\
\text { Facilities }\end{array}$ & 8 & 2.0 & 8 & 2.0 \\
\hline Outreach AWC & 213 & 53.3 & 294 & 73.5 \\
\hline \multicolumn{5}{|c|}{ Immunization site convenient } \\
\hline Yes & 388 & 97.0 & 391 & 97.8 \\
\hline No & 12 & 3.0 & 9 & 2.3 \\
\hline \multicolumn{5}{|c|}{ ASHA visited after side effects } \\
\hline Yes & 142 & 67.3 & 126 & 56.0 \\
\hline No & 69 & 32.7 & 99 & 44.0 \\
\hline \multicolumn{5}{|c|}{ Taken for next dose after adverse effect } \\
\hline Yes & 190 & 90.0 & 179 & 79.6 \\
\hline No & 21 & 10.0 & 46 & 20.4 \\
\hline
\end{tabular}




\begin{tabular}{|l|l|l|l|l|}
\hline \multicolumn{2}{|l|}{ Received four key messages } & 25.3 & 197 & 26.5 \\
\hline $\begin{array}{l}\text { Which vaccines and } \\
\text { they prevent which } \\
\text { diseases }\end{array}$ & 216 & 25.0 & 162 & 21.8 \\
\hline $\begin{array}{l}\text { Side-effects of vaccines } \\
\text { \& management } \\
\text { explained }\end{array}$ & 213 & 23.0 & 150 & 20.2 \\
\hline $\begin{array}{l}\text { When and where to } \\
\text { come for the next } \\
\text { immunization }\end{array}$ & 196 & 12.4 & 95 & 12.8 \\
\hline $\begin{array}{l}\text { Remember to bring a } \\
\text { card during the next } \\
\text { visit }\end{array}$ & 106 & 14.3 & 140 & 18.8 \\
\hline $\begin{array}{l}\text { Did not receive any } \\
\text { message/no time to } \\
\text { discuss }\end{array}$ & 122 & 11.3 & 71 & 17.8 \\
\hline Heard negative stories about immunization & 45 & 88.8 & 329 & 82.3 \\
\hline Yes & 355 & & \\
\hline No & & & \\
\hline
\end{tabular}

Table 2. Distribution of Individual and Socio-Demographic Factors in Mewat, Haryana 2019-20

\begin{tabular}{|c|c|c|c|c|c|c|c|}
\hline \multirow{3}{*}{ Variable } & \multirow{2}{*}{\multicolumn{2}{|c|}{$\begin{array}{l}\begin{array}{l}\text { Completely } \\
\text { immunized }\end{array} \\
(\mathrm{N}=426)\end{array}$}} & \multirow{2}{*}{\multicolumn{2}{|c|}{$\begin{array}{l}\text { Partially / } \\
\text { Unimmunized } \\
(\mathrm{N}=374 \\
\end{array}$}} & \multirow{3}{*}{$\begin{array}{l}\text { Odds Ratio } \\
\text { OR }(95 \% \mathrm{CI}) \\
\text { value }\end{array}$} & \multirow{3}{*}{$\begin{array}{l}\text { Adjusted Odds } \\
\text { Ratio } \\
\text { AOR (95\% CI) } \\
\end{array}$} & \multirow[t]{3}{*}{ P-value } \\
\hline & & & & & & & \\
\hline & No. & $\%$ & No. & $\%$ & & & \\
\hline \multicolumn{8}{|l|}{ Area of residence } \\
\hline Urban & 215 & 53.7 & 185 & 46.3 & & & \\
\hline Rural & 211 & 52.7 & 189 & 47.3 & $0.96(0.72-1.26)$ & $0.80(0.58-1.1$ & 0.19 \\
\hline \multicolumn{8}{|l|}{ Primary caregiver } \\
\hline Mother & 362 & 50 & 361 & 50 & & & \\
\hline Others & 64 & 83.1 & 13 & 16.9 & $0.20(0.11-0.37)$ & & 0.00 \\
\hline \multicolumn{8}{|l|}{ Religion } \\
\hline Hindu & 272 & 72.9 & 101 & 27.1 & & & \\
\hline Muslim & 154 & 36 & 273 & 64 & $4.77(3.52-6.45)$ & $4.94(3.64-6.71)$ & 0.00 \\
\hline \multicolumn{8}{|l|}{ Caste } \\
\hline Hindu OBC and others & 272 & 72.9 & 101 & 27.1 & & & \\
\hline Muslim backward class & 154 & 36 & 273 & 70 & $4.77(3.52-6.45)$ & & 0.00 \\
\hline \multicolumn{8}{|l|}{ Gender } \\
\hline Male & 229 & 55.4 & 184 & 44.6 & & & \\
\hline Female & 197 & 50.9 & 190 & 49.1 & $1.20(0.90-1.58)$ & $1.40(1.03-1.90)$ & 0.02 \\
\hline \multicolumn{8}{|l|}{ Religion wise gender } \\
\hline Others religion male & 336 & 59.4 & 229 & 40.6 & & & \\
\hline Muslim Male & 90 & 38.3 & 145 & 61.7 & $2.36(1.73-3.22)$ & & 0.00 \\
\hline \multicolumn{8}{|l|}{ Birth Oder } \\
\hline$\leq 2$ & 261 & 56.3 & 179 & 40.7 & & & \\
\hline$>2$ & 165 & 45.8 & 195 & 54.2 & $1.72(1.30-2.28)$ & & 0.00 \\
\hline \multicolumn{8}{|l|}{ MCP card } \\
\hline Available & 292 & 62.3 & 176 & 37.7 & & & \\
\hline Not available & 134 & 40.3 & 198 & 59.7 & $2.45(1.83-3.27)$ & & 0.00 \\
\hline \multicolumn{8}{|l|}{ Maternal education } \\
\hline Primary and above & 284 & 68.9 & 128 & 31.1 & & & \\
\hline
\end{tabular}




\begin{tabular}{|c|c|c|c|c|c|c|c|}
\hline No education & 142 & 36.6 & 246 & 63.4 & $3.84(2.86-5.15)$ & $2.72(1.85-3.99)$ & 0.00 \\
\hline \multicolumn{8}{|l|}{ Father education } \\
\hline Primary and above & 275 & 67 & 135 & 33 & & & \\
\hline No education & 151 & 38.7 & 239 & 61.3 & $3.22(2.41-4.30)$ & $1.63(1.08-2.49)$ & 0.02 \\
\hline \multicolumn{8}{|l|}{ Employment } \\
\hline $\begin{array}{l}\text { Employed/Self } \\
\text { employed }\end{array}$ & 285 & 59.5 & 194 & 40.5 & & & \\
\hline Unemployed & 141 & 43.9 & 180 & 56.1 & $1.87(1.40-2.49)$ & $1.16(0.81-1.66)$ & 0.39 \\
\hline \multicolumn{8}{|c|}{ Monthly income (in Rupees) } \\
\hline More than 5000 & 366 & 54.3 & 307 & 45.7 & & & \\
\hline Less than 5000 & 60 & 47.2 & 67 & 52.8 & $1.33(0.91-1.94)$ & $0.94(0.60-1.45)$ & 0.78 \\
\hline \multicolumn{8}{|c|}{ Parity status (number of living children) } \\
\hline$\leq 4$ Children & 385 & 56.7 & 293 & 43.3 & & & \\
\hline$>4$ Children & 41 & 33.6 & 81 & 66.4 & $2.59(1.73-3.89)$ & $1.47(0.94-2.28)$ & 0.08 \\
\hline \multicolumn{8}{|l|}{ Place of vaccination } \\
\hline Govt/Pvt & 207 & 70.6 & 86 & 29.4 & & & \\
\hline Outreach & 219 & 43.2 & 288 & 56.8 & $3.16(2.32-4.30)$ & $2.34(1.68-3.24)$ & 0.00 \\
\hline \multicolumn{8}{|c|}{ Received 4 Key messages } \\
\hline Received & 312 & 57.9 & 227 & 42.1 & & & \\
\hline Did not receive & 114 & 43.7 & 147 & 56.3 & $1.77(1.31-2.38)$ & & 0.00 \\
\hline \multicolumn{8}{|c|}{ Distance to health facility (in walk time) } \\
\hline$\leq 30$ minutes & 418 & 54 & 356 & 46 & & & \\
\hline$>30$ minutes & 8 & 30.7 & 18 & 69.3 & $2.64(1.13-6.14)$ & & \\
\hline \multicolumn{8}{|c|}{ Aware of next due dose of vaccine } \\
\hline Aware & 317 & 60.7 & 205 & 39.3 & & & \\
\hline Not Aware & 109 & 39.2 & 169 & 60.8 & $2.39(1.77-3.23)$ & $1.95(1.41-2.68)$ & 0.00 \\
\hline \multicolumn{8}{|c|}{ Received Anganwadi services } \\
\hline Yes & 215 & 59.3 & 147 & 40.7 & & & \\
\hline No & 211 & 48.1 & 227 & 51.9 & $1.57(1.18-2.08)$ & & \\
\hline \multicolumn{8}{|c|}{ Decision maker for immunization } \\
\hline Primary care giver & 205 & 58 & 148 & 42 & & & \\
\hline Mainly Husband & 221 & 49.4 & 226 & 50.6 & $1.41(1.06-1.87)$ & 0.0007 & \\
\hline \multicolumn{8}{|l|}{ Birth } \\
\hline $\begin{array}{l}\text { Attended by the health } \\
\text { worker }\end{array}$ & 378 & 54.7 & 312 & 45.3 & & & \\
\hline $\begin{array}{l}\text { Not attended by health } \\
\text { worker }\end{array}$ & 48 & 43.6 & 62 & 56.4 & $1.56(1.04-2.34)$ & $0.97(0.62-1.52)$ & 0.78 \\
\hline
\end{tabular}

Table 3. Full Immunization Status of Study Participants in Mewat (12-23 months children)

\begin{tabular}{|l|l|l|l|}
\hline Immunization status & Urban & Rural & Total \\
\hline Eligible for Full immunization & 157 & 166 & 323 \\
\hline Fully immunized & 92 & 100 & 192 \\
\hline \% Fully immunized & 59 & 60 & 59 \\
\hline
\end{tabular}




\section{Haryana: Immunization Coverage in Various Surveys}

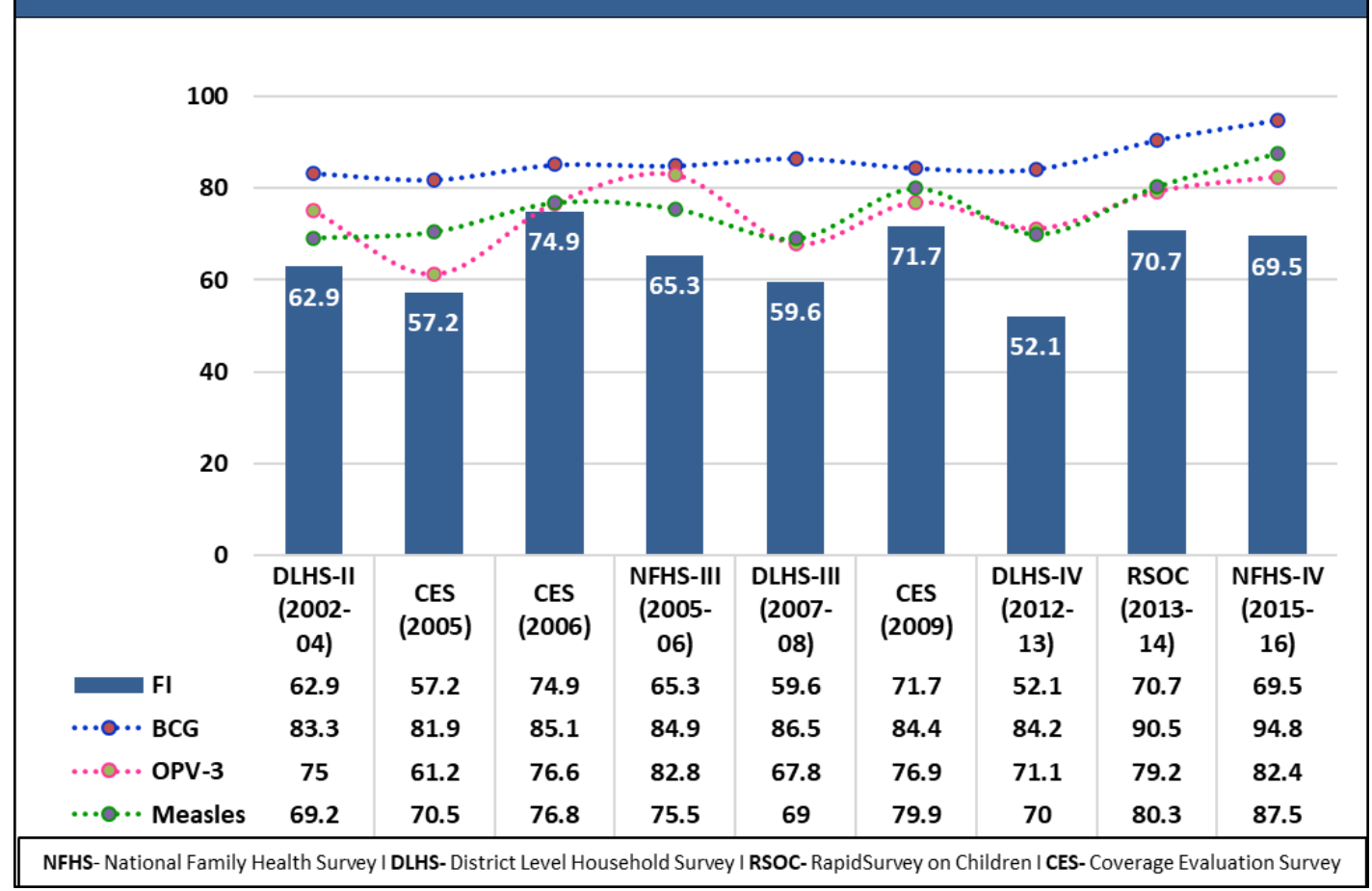

Figure 1. Haryana Full Immunization Coverage in Various Surveys 2002-2016

\section{Mewat: Immunization Coverage in Various Surveys}

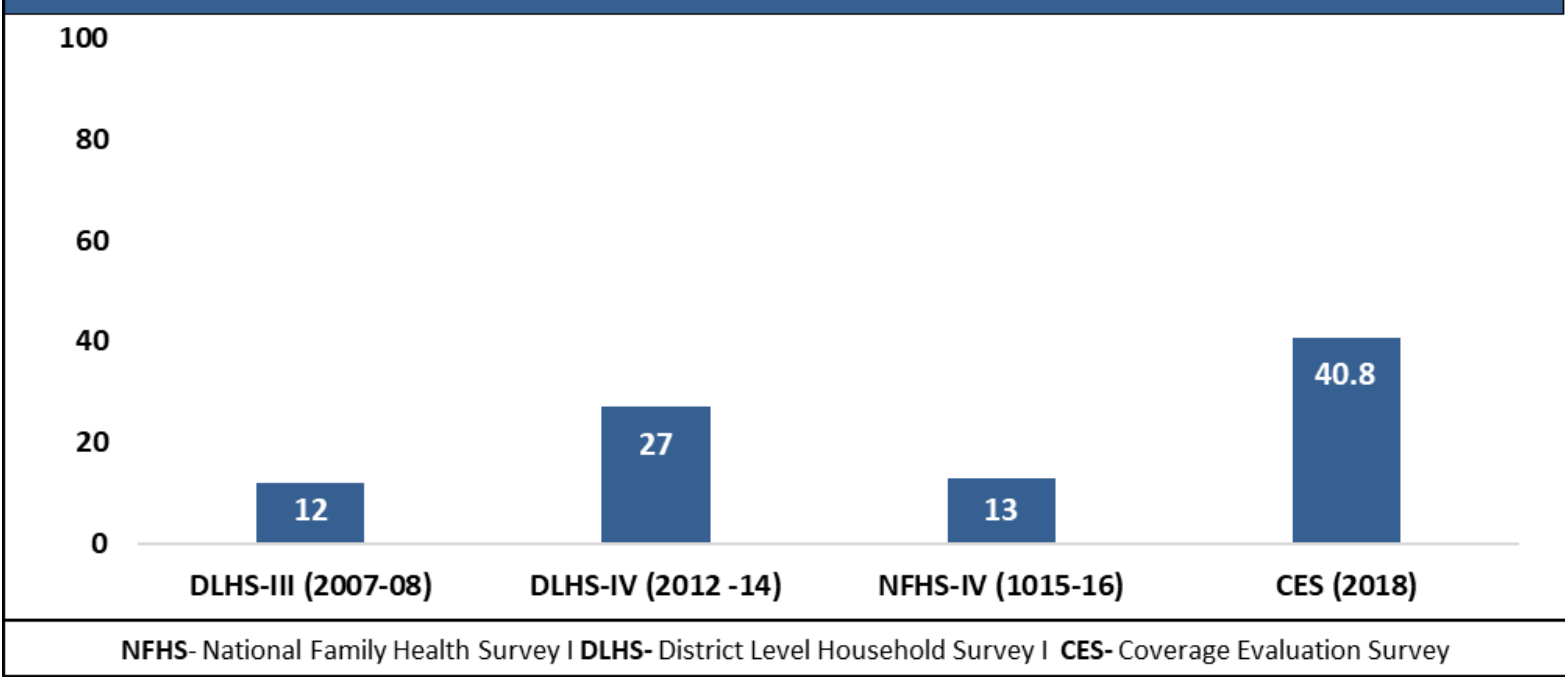

Figure 2. Mewat Full Immunization Coverage in Various Surveys 


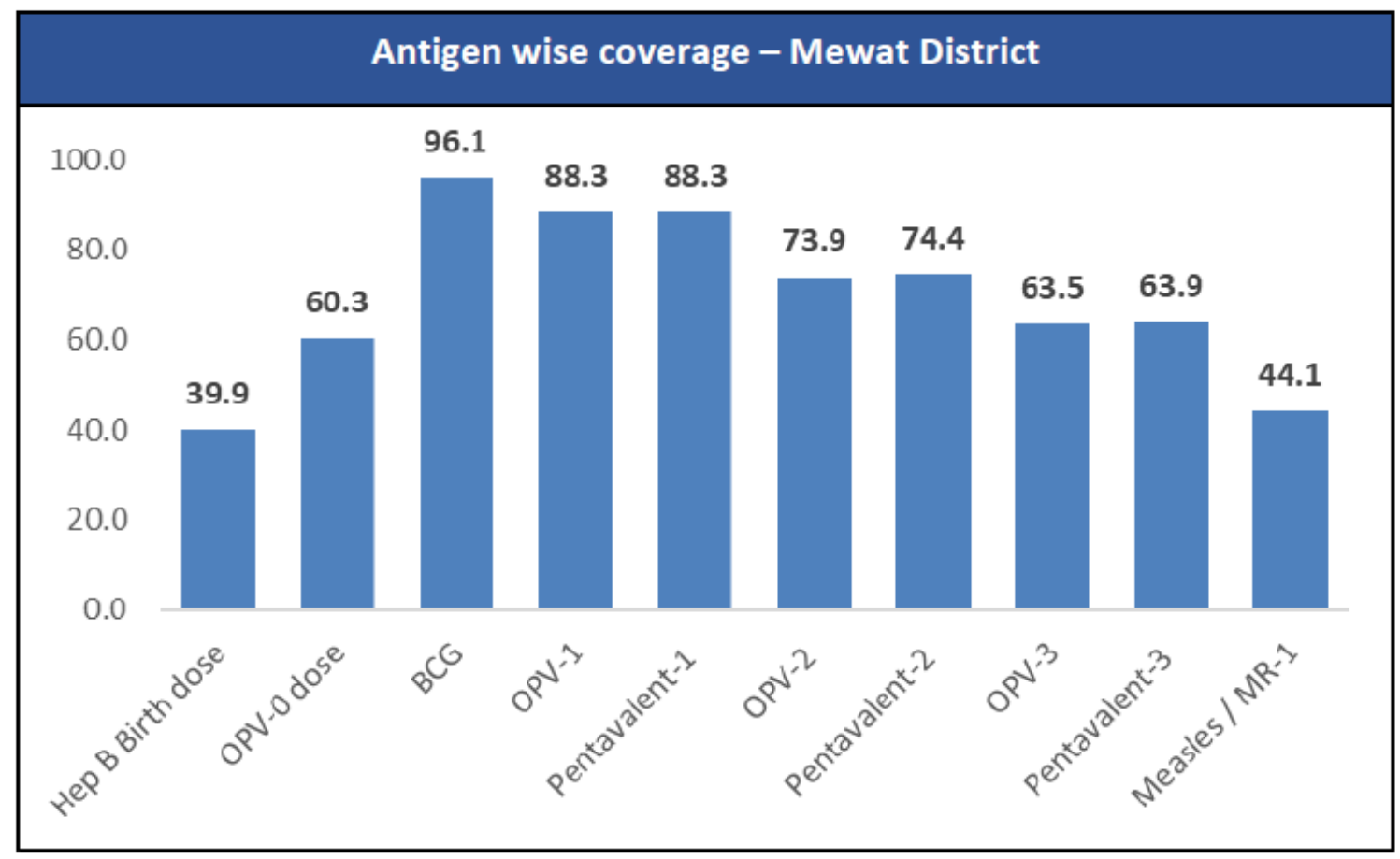

Figure 3. Antigen Wise Coverage in the Study Population -Mewat District 2019-2020

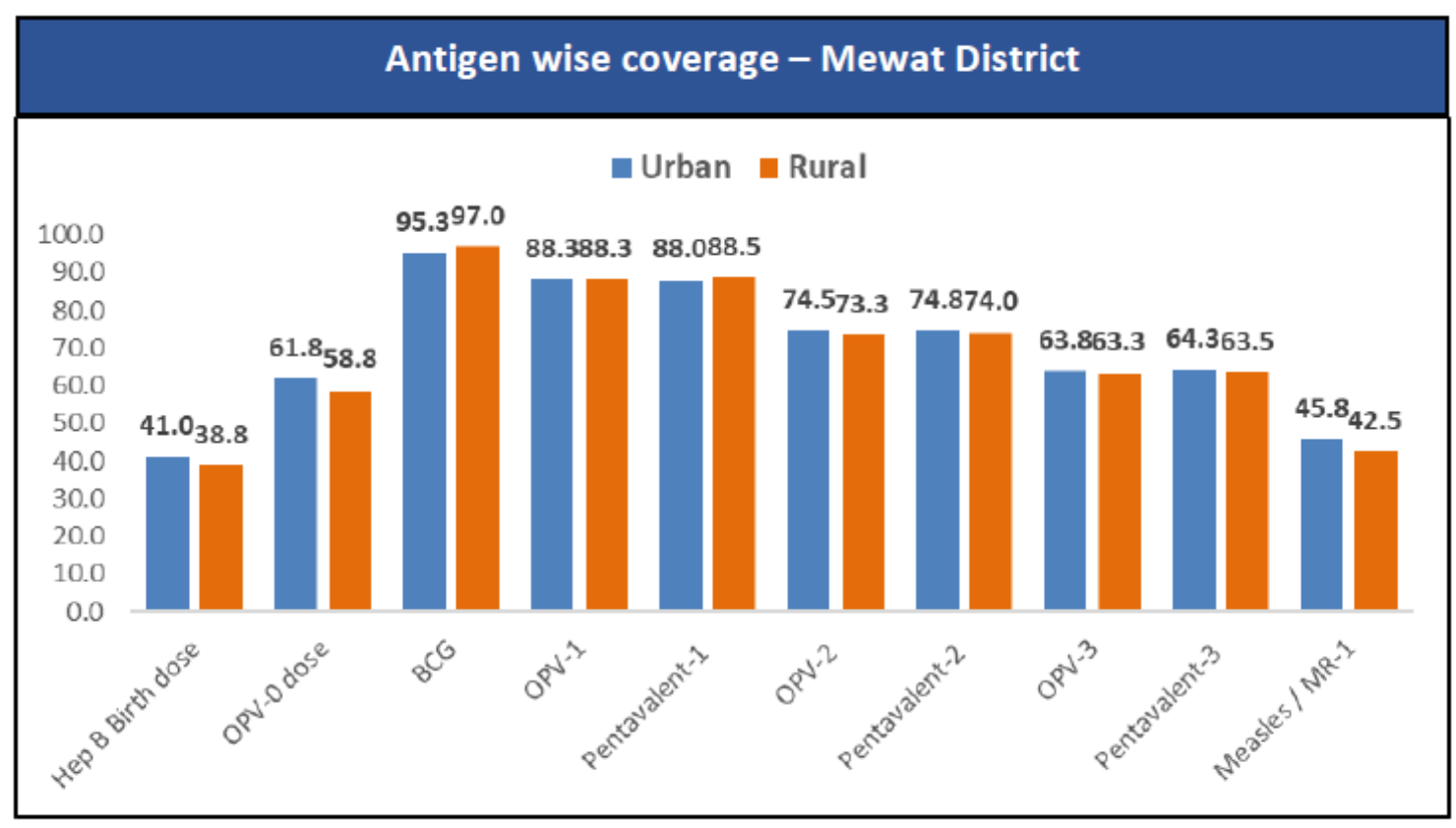

Figure 4. Urban -Rural Antigen Wise Coverage in Study Area of District Mewat 2019-20

\section{Factors Associated with Full Immunization Status of Children}

On the bi-variable analysis, birth order of the child, mothers age, parental educational status, number of living children in the family, employment, religion, caste, place of vaccination, awareness about next due dose of vaccine, the presence of a professional birth attendant in the delivery process, decisionmaker for immunization in the family, distance to a health facility were found to be significantly associated with children's full immunization status. However, in the multivariate analysis, religion, gender, parental education, place of vaccination, and next due 
dose of vaccine by mother were significantly associated (Table 2).

Table 2 shows that mothers who attained primary or higher education levels were 3.84 times more likely to have fully immunized children than illiterate mothers (Adjusted Odds Ratio (AOR) $=2.72 \quad 95 \% \quad \mathrm{CI}=1.85-3.99)$. Mothers who had good knowledge and awareness about the next due dose about immunization were 1.9 times more likely to have a fully immunized child than those who had poor knowledge (AOR $=1.95, \quad 95 \%$ $\mathrm{CI}=1.41-2.68)$. Children of the Hindu religion were 4.9 times more likely to have fully immunized than Muslim religion ( $\mathrm{AOR}=4.94,95 \% \mathrm{CI}=3.64-6.71)$. Children born in health institutions had 2.34 times more chance of being fully vaccinated than children born at home $(\mathrm{AOR}=2.34,95 \% \mathrm{CI}=1.68-3.24)$. Children with male gender had 1.4 times more chance of being fully immunized than female gender $(\mathrm{AOR}=1.40,95 \% \mathrm{CI}=1.03-1.90)$.

Younger mothers $(<20$ years of age) were less likely to vaccinate their children than older mothers (AOR=4.1,95\% CI=1.94-8.71).

Figure 3 shows antigen wise coverage among 0-23 months children; BCG had the highest coverage $(96.1 \%)$, followed by a first, second, and third dose of oral polio vaccine and Pentavalent vaccines. Overall, a decreasing trend was observed with OPV-1 (88.3\%), Pentavalent-1 $(88.3 \%)$ to OPV-3 $(63.5 \%)$, Pentavalent-3 (63.9\%) and further fall was observed for MCV-1 (44.1\%). The dropout rates from $\mathrm{BCG}$ to $\mathrm{MCV}-1$ was $15.6 \%$, while Pentavalent-1 to Pentavalent-3, it was $7.2 \%$.

Figure 4 shows the overall vaccination coverage of each vaccine in urban and rural areas. Overall, Hep B vaccination coverage at birth was 319 (39.9\%), which was the lowest compared to other antigens. It was $38.8 \%$ for rural and $41 \%$ in urban areas. Overall OPV-0 dose vaccination coverage was $60.3 \%$, while, in urban and rural areas, it was $61.8 \%$ and $58.8 \%$, respectively. Overall, BCG vaccination coverage was $96.1 \%$, while, in urban and rural areas, it was $95.3 \%$ and $97 \%$, respectively. OPV1 vaccination coverage was $88.3 \%$ and $88.3 \%$ in urban and rural areas, respectively, while overall it was $88.3 \%$. Pentavalent 1 vaccination coverage was $88 \%$ and $88.5 \%$ in urban and rural areas, respectively, while overall it was $88.3 \%$. OPV2 vaccination coverage was $74.5 \%$ and $73.3 \%$ in urban and rural areas, respectively, while overall it was $73.9 \%$. Pentavalent 2 vaccination coverage was $74.8 \%$ and $74 \%$ in urban and rural areas, respectively, while overall it was $74.4 \%$. OPV3 vaccination coverage was $63.8 \%$ and $63.3 \%$ in urban and rural areas, respectively, while overall it was $63.5 \%$. Pentavalent 3 vaccination coverage was $64.3 \%$ and $63.5 \%$ in urban and rural areas, respectively, while overall it was $63.9 \%$. Overall, measles-rubella vaccination coverage was $44.1 \%$, while, in urban and rural areas, it was $45.8 \%$ and $42.5 \%$, respectively. Overall, DPT booster 1 coverage was $15.5 \%$ and MR2 coverage was $15.6 \%$ at the district. The dropout rate for BCG to measles-rubella vaccine in the age group of (12-23 months) in urban was $12.5 \%$, while it was $18.4 \%$ in rural, whereas the overall dropout rate was $15.6 \%$. The dropout rate for pentavalent 1 to pentavalent 3 in urban was $11.3 \%$, while it was $11.9 \%$ in rural areas, whereas the overall dropout rate was $11.7 \%$. The dropout rate for OPV1 to OPV3 in urban areas was $12 \%$, while it was $11.4 \%$ in rural areas; the overall dropout rate for OPV1 to OPV3 was $11.76 \%$. The dropout rate for MR1 to MR2 in urban areas was $57.14 \%$, while it was $52.6 \%$ in rural areas; the overall dropout rate at the district level was $54.8 \%$.

More than half $(51.6 \%)$ of the respondents chose government facilities for the delivery, one-third $(34.6 \%)$ chose private health facilities for a delivery while, $13.8 \%$ delivered at home. The majority $(77 \%)$ of the respondents chose government health facilities for delivery in Punhana block while only one-third in Taoru block. Overall availability of immunization card in the district was $58.5 \%$, maximum in Taoru block $75 \%$, and minimum in Nuh block $40 \%$. Decisions regarding vaccination of the children were dependent on either their husband or family members. The prime influence was the husband in $54.3 \%$ at the district level $62.3 \%$ in rural areas and $46.3 \%$ in the urban areas.

Overall, $426(53.3 \%)$ children in the age group of 0-23 months were fully immunized, $345(43.1 \%)$ were partially immunized and 29 $(3.6 \%)$ completely unimmunized. Notably, $46.7 \%$ of the children did not receive ageappropriate immunization. Only $18.3 \%$ of the children were immunized on time as per age in 
0-23 months. The most common reason for no immunization/partial immunization was fear of side effects of vaccines $(28 \%)$, followed by the awareness gap (24\%), child traveling (21\%), and operational reasons (16\%), as shown in Figure 5.

Among children aged 12-23 months, timely immunization was seen in $3.1 \%$ and delayed in more than half $(56.3 \%)$ of the children. About $38.4 \%$ of children were partially immunized, and $2.2 \%$ did not receive any vaccines. The common reason for no or partial immunization was lack of awareness in (32\%) followed by fear of side effects of the vaccine (27\%) of the children, as shown in Figure 6.

Reasons for 426 fully vaccinated (age appropriate vaccination) children aged 0-23 months were analyzed. It was observed that 145 (34\%) caregivers accepted immunization after counseled by the health workers regarding benefits of immunization. zing their children, $221(51.9 \%)$ replied that vaccines prevent children from diseases.About 51(12\%) trusted health system and vaccines and only 9 (2.1\%) were self motivated to get their children vaccinated.

Reasons for 374 partially and unimmunized children were also analyzed in detail. The most common reason for partial or no immunization was fear of adverse events following vaccination in $119(27 \%), 93(21.5 \%)$ child away from home, 57 (13\%) no one contacted the family, $67(15.2 \%)$ immunization session not held, $24(5.5 \%)$ family not aware of the need of immunization and $18(4.1 \%)$ were unaware of the missed dose,12 (2.7\%) child was sick and caregiver did not opt for vaccination, $12(2.7 \%)$ family was resistant to immunization, $4(0.9 \%)$ had concern for loss of wages, $3(0.7 \%)$ caregiver not opted for multiple injections, $2(0.5 \%)$ vaccine was not available at session site and $24(5.5 \%)$ did not specify any reason for not getting immunized.

\section{Age appropriate immunization ( $0-23$ months) - Mewat District}

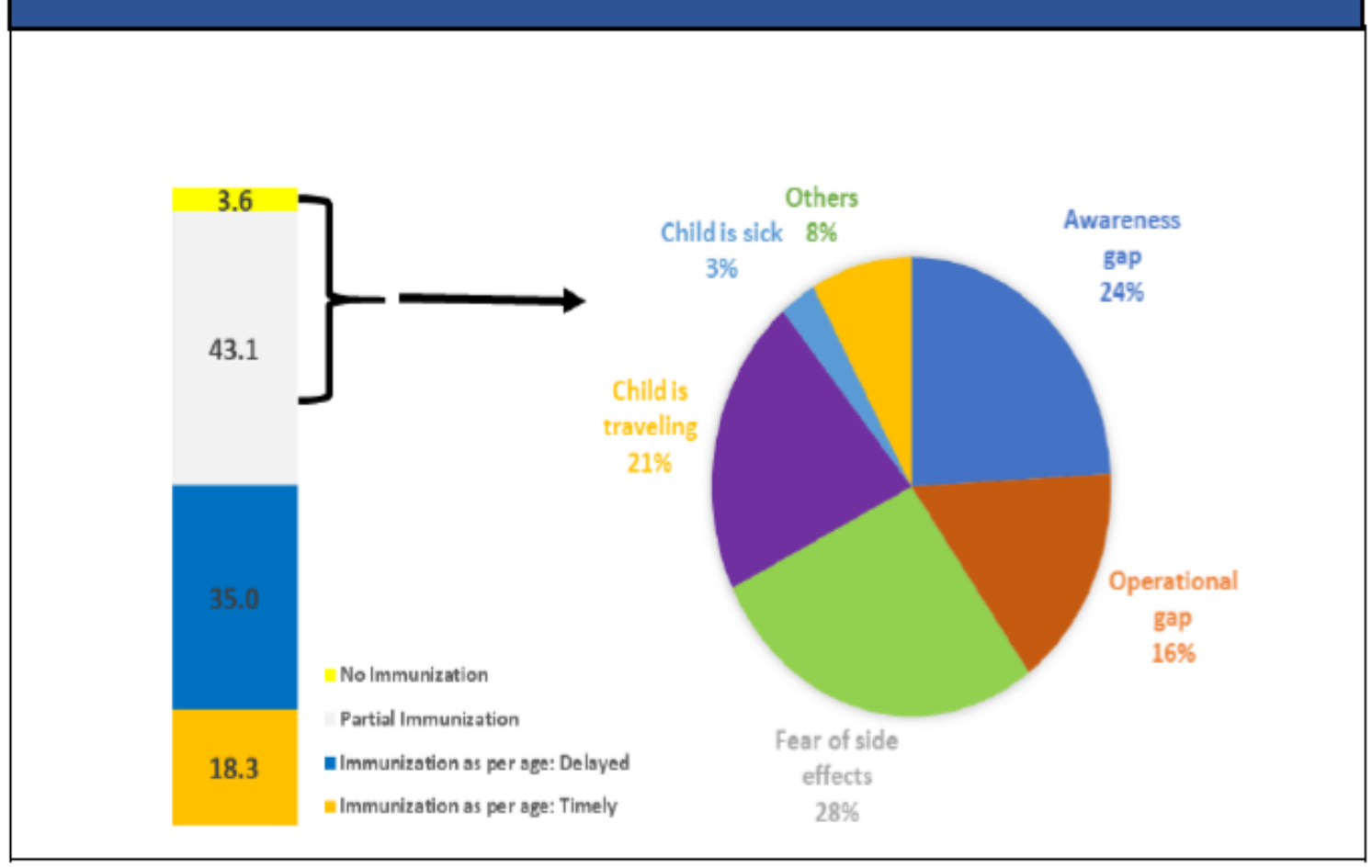

Figure 5. Age Appropriate Immunization in the Study Area in 0-23 Months Children in Mewat 2019-2020 


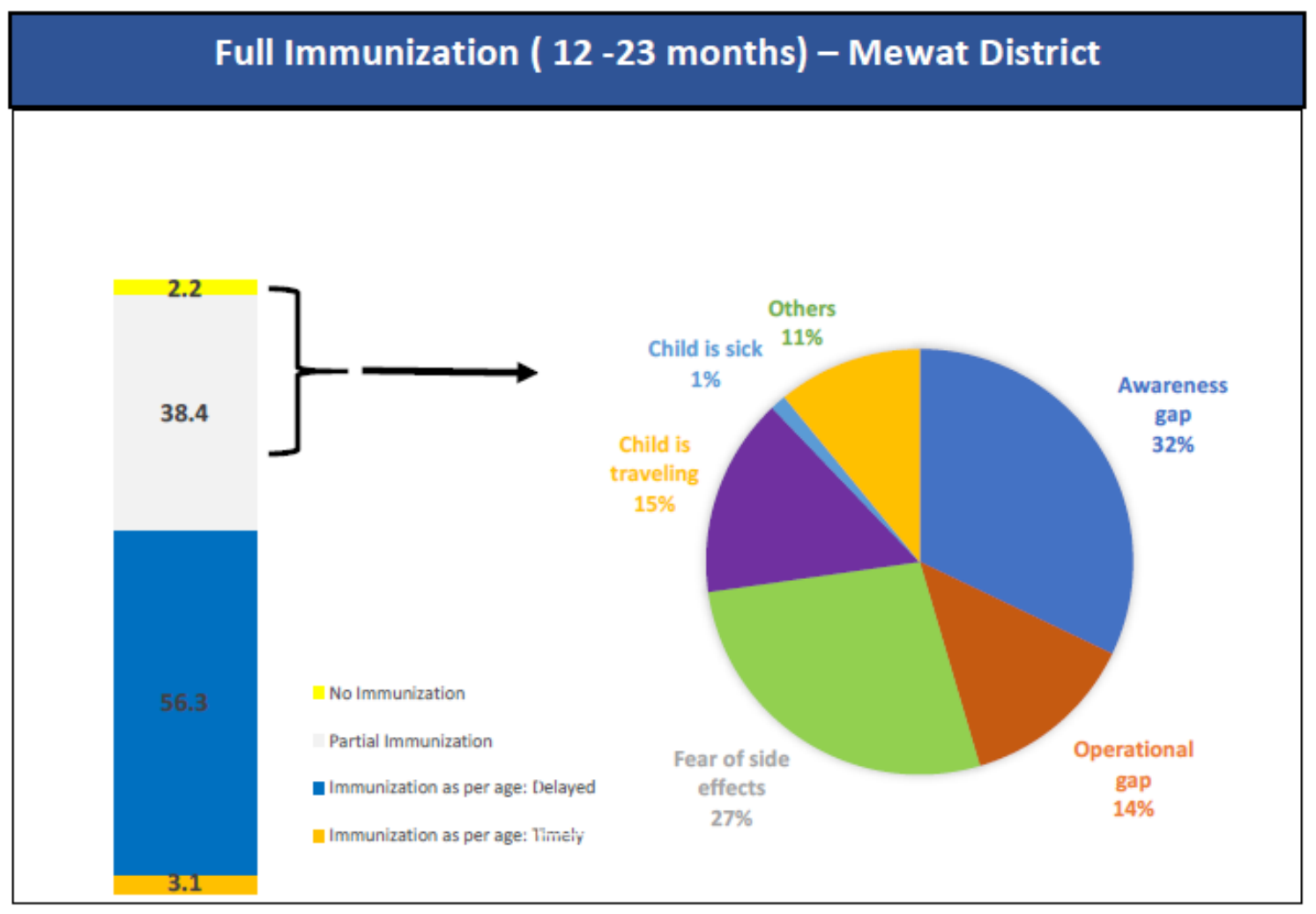

Figure 6. Full Immunization in the Study Area in 12-23 Months Children in Mewat 2019-2020

\section{Discussion}

A total of 800 children (400 from urban areas and 400 from rural areas) aged 0-23 months were residing in the rural and urban areas of district Mewat were included in the study. The coverage of fully immunized children in the study area was found to be $59 \%$ (59\% in urban area and 60\% in rural area) to be quite high as compared to National Family Health Survey (NFHS-4) (2015-16) district figures i.e., $13.1 \%$ (rural 11\%) indicating that there has been a significant improvement in overall immunization coverage of all vaccines in recent years, as a result of continuous efforts being put in to achieve universal immunization coverage by the government. Similarly, the coverage in this study was higher when compared to the District Level Household Survey (DLHS-4) (2012-13), where the percentage of fully immunized children was only $27.3 \%$ in the district (rural 20.8\%). Mewat district had the highest percentage (46\%) of "partially immunized" and 16\% "no immunized" children in 2018 [16]. All other Haryana districts had full immunization coverage (FIC) of more than $60 \%$. Coverage evaluation survey (CES) in 2018 had also shown that the percentage of children aged 12-
23 months who received full immunizations increased from $13.1 \%$ in $2015-16$ to $40.8 \%$ in Mewat.

Our findings revealed that more than onethird $(40.6 \%)$ of the children in $12-23$ months age group were "partially immunized" or had "no immunization." More than one-third (37.4\%) of the primary caregivers were not aware of the vaccine's next due date in the present study, which was similar to the study conducted in Bijapur, Karnataka [17]. Full immunization coverage in the district still falls short of the WHO and UNICEF's Global Immunization Vision and Strategy goal of $80 \%$ coverage [18].

Factors affecting the childhood vaccinations are more complex and multifactorial. Various factors included the locality (urban/rural/slums) of residence $[19,20]$ parental education $[21,22]$ socioeconomic status of the households [23, 24, 25] caste and religion [26, 27], parity and mother's age at birth [28, 29] and distance to health service centers [30, 31]. Gender discrimination disfavoring female child is also an essential determinant of childhood vaccination in India [28, 29]. Parental education, religion, employment, family size, and place of delivery were the main 
demographical factors that affected immunization in the district. Mothers were the primary caregiver in the majority of the cases in our study. Approximately half of the primary caregivers $(48.5 \%)$ in the study were not having any formal education. Overall low literacy rate of $54.08 \%$ (males $69.9 \%$; females $36.6 \%$ ) in the district probably contributed to the ignorance and blind beliefs or myths among the beneficiary's families and society. Illiterate parents were not aware of the benefits of immunization and its schedule and had shown a lack of interest in the child's vaccination. Decisions for vaccination of the children were dependent either on their husband or elderly male family members. Only $3.8 \%$ of primary caregivers independently decided to get their children vaccinated. About one-third of primary caregivers believed that immunization makes their children sterile.

The institutional births had improved from $37.6 \%$ in $2015-16$ to $86.3 \%$ during the study period. We found that improvement in the institutional delivery rates and availability of the professional birth attendant during the delivery process had a positive and significant association with children's immunization status. Higher immunization coverage were seen in the studies where professional birth attendant were present during the process [32, 33]. The auxiliary nursing midwives (ANMs) provide antenatal, perinatal, nutrition \& reproductive advices, and immunization services in villages. They are accepted by the local community and play important role in mobilizing them for vaccination.

During our study, it was revealed that maternal age was significantly associated with immunization coverage. There were 3.5 times more chances of children being fully vaccinated if the maternal age was more than 20 years $(\mathrm{AOR}=3.53,95 \%$ CI 1.75-7.10). Children of older mothers were more likely to be fully immunized. Our study results were similar to the study conducted by [34]. Women under 20 years of age in Mewat may be less likely to make their own decisions regarding vaccinating their children; mainly husbands and family members are the decision-makers. Older mothers are likely to have more experience raising children and more likely to be knowledgeable about children's health, which may be the possible explanation of improved coverage at this age.

In the present study, coverage for the BCG vaccine was remarkably high, indicating a certain healthcare services access by the community. BCG vaccine is provided at the time of birth in government institutions, and an increase in institutional deliveries in recent years may be a contributing factor. The gradual decrease in the vaccination coverage from the birth-administered BCG to DPT3/ Pentavalent3 given at age six months could be secondary to difficulty in accessing immunization services, lack of understanding for the need for further vaccination, loss in motivation or perceived need for child vaccination, or a combination of all these factors. Difficulty in accessing health services could be explained, at least in part, by institutional and societal discrimination directed at parents belonging to lower socioeconomic strata, castes and poorer households, and physical barriers such as unavailability of services due to long distances to health centers, and unavailability of health workers at the health centers.

Usually, children in urban areas had been reporting to have better vaccination outcomes than children residing in rural areas. The proportion of fully vaccinated children was slightly better in urban areas $(53.7 \%)$ than in rural areas $(52.7 \%)$; however, we did not find any significant difference in our study. An extensive network of community health workers (Anganwadi and ASHA workers) in rural areas of Mewat and their task is to mobilize children and pregnant women to receive immunization services; a comparable network may not exist in urban areas may the possible reason. This could partially account for our finding that urban children with the same level of poverty, education, religion, and caste as rural children still have lower chances of being fully vaccinated, with significant implications for targeted immunization intervention programs and related policies. The urban areas in Mewat have both middle-class neighborhoods and large concentrations of poor and uneducated families (of Muslim religion), who mostly lack of awareness about the benefits of immunization. It was found in the study that women do not get their children adequately immunized, saying that multiple injections hurt $(7.8 \%)$ their children and cause 
other kinds of side-effects (61.2\%). They were also of the view that their children were doing well without immunization; hence there was no need to give them pain by the injections. Findings revealed that overall awareness for the next vaccination due date was among $61 \%$ of primary caregivers. In the present study, most respondents cited the main reason for low immunization was the awareness gap followed by fear of side effects. Awareness about vaccination plays a critical role in vaccine acceptance. Information regarding the immunization schedule and the next due date of vaccination allows mothers and caregivers to plan well in advance, reducing the probability of missed vaccinations. Similar results have been shown in a study conducted $[35,36]$. in Lucknow district, and Nath B in urban slums of Lucknow [37] stated that low awareness was the most common reason for partial or no immunization from Kakinada, Andhra Pradesh [38] showed that the most common reasons for partial/no immunization were an ill child (27.5\%), lack of knowledge about vaccination (25.12\%), migration to other places with no understanding of place and time of vaccination (17.5\%). A study [39] from the rural area of district Tonk, Rajasthan showed the most common reason for partial/nonimmunized was sickness $22(36.06 \%)$ of an elder sibling because of the previous vaccination followed by $20(32.07 \%)$ of the illness of the beneficiary at the time of vaccination. A study [40] in tertiary care hospital of North India showed that the common reasons for partial immunization and non-immunization were lack of knowledge about vaccination $(30.3 \%)$, apprehension about side effects of vaccination (28.8\%), and lack of knowledge about subsequent doses (22.09\%). Another focal study from Surajgarha Block, [41] was 55.2\%. In rural Uttar Pradesh, it was $50 \%$ as per [42]. The full immunization coverage was much lower in the studies from Bihar and Uttar Pradesh. This may be attributed to the lower awareness level and fewer health services utilization in both the territories.

In the present study, $59.4 \%$ of children were fully immunized in the age group of 12-23 months in a rural area of Tripura [43] highlighted in their research that the main reasons for low immunization are the lack of knowledge $(26.7 \%)$, any illness of the child (26.7\%), followed by fear of possible adverse effects (20\%). The consolidated Intensified Mission Indradhanush report stated the reason for non-vaccination were awareness issues (45\%), AEFI apprehension (24\%), vaccine resistance $11 \%$ ), child traveling $(8 \%)$, and program-related gaps in $4 \%$ of the respondents. Our research found that most Mewat children who received partial immunizations missed the pentavalent vaccine (DPT, Hepatitis B and Haemophilus influenza b) and measles vaccine. The dropout rate for BCG to measles in the present study was $54 \%$ and pentavalent- 1 to pentavalent-3 was $27.5 \%$. Dropout rates were much higher in our study than the research conducted in Tamil Nadu [44], the dropout rate from BCG to measles was $15.9 \%$ and pentavalent-1 to pentavalent-3 was $4.1 \%$. Pentavalent vaccine consists of a series of three injections, and children with partial immunizations had received the first one or two injections. During our study, we found the most common reason for partial or no immunization was fear of side effects following vaccination. Also, we found a significant drop out of $54 \%$ in BCG to measles-rubella1. The possible explanation may be that mothers forget to have their children immunized once they reach a certain age, such as nine months, the period for measles vaccination.

Commonly, DPT vaccine coverage is accepted as the standard reflecting immunization program performance. The first DPT/ Pentavalent vaccine dose is an indicator of access to health care services. The third DPT/Pentavalent dose coverage demonstrates the family's ability to access and utilize immunization services in multiple visits. The high dropout (more than 10\%) of DPT/Pentavalent services in Mewat shows that information regarding the benefits of immunization and the need for multiple immunization visits have not reached all the mothers. Our study had revealed the highest coverage $(97.5 \%)$ with BCG vaccine. It is administered up to first 15 days as a birth dose and up to one year of the age. The increasing number of institutional delivered babies with the help of health workers played a significant role in increasing the coverage of BCG vaccination.

In the present study, we found the availability of immunization cards with $58.5 \%$ of the beneficiaries on the survey's date. The 
vaccination card availability was the highest (75\%) of the children in Taoru block and the lowest in Nuh block (40\%). Our study results were similar to a tribal block of Thane district [45]. In the study conducted in Surajgarha block of Bihar [41], and the availability was $65.7 \%$ and $88.4 \%$ in the study executed in urban slums of Ahmedabad city [46].

In our study $43.3 \%$ (36/83) Muslim male children were fully immunized as compared to 80.9\% (68/84) Hindu male children. Similarly, $34.2 \%$ Muslim female children were fully immunized as compared to $74.4 \%$ Hindu female children. Overall, gender disparity in full immunization was highest among Muslims compared to Hindus. Girls born in India have a $40 \%$ higher risk of ill-health as compared to boys and are less likely to access healthcare services, including immunization. Girls have lower immunization coverage than boys also reinforce the findings of previous studies of gender disparities in childhood immunization. Evidence outside India indicates more significant gender-based discrimination among Muslims than non-Muslim religions [47, 48]. A recent study has documented son preference among various religious groups in India and found that women from Muslim households have a slightly higher son preference. Women from other non-Hindu, non-Muslim religions, have slightly lower preference for sons than the Hindu and Muslim women. Among Muslims, lack of education, and relatively poor socioeconomic status (due to the patriarchal social setup and ideology) may produce circumstances leading to son being the most dependable socioeconomic insurance [49]. Such consideration may have resulted in gender discrimination healthcare utilization among Muslim children.

Mothers/caregivers having Muslim as their religion were less likely to be fully immunized. Most Muslims are often not formally educated and not in employment. Immunization activities are perceived to be deliberately designed by outsiders (enemies of Islam) to reduce the Muslim population through vaccines' fortification [50]. Misconceptions like this could have flown over to countries, including India. Children from Hindu religious affiliations had better vaccination coverage. The factors affecting childhood vaccination in the Indian states of Madhya Pradesh, Bihar,
Uttar Pradesh, and Rajasthan [51]. It showed that children are more likely to receive immunization if their parents are a couple, with the father literate and the mother with at least a middle-school-education level who received antenatal care or delivered in an institutional environment. The importance of maternal education in children's health is universally recognized. Children of more educated mothers are more likely to be fully immunized $[52,53]$. A woman with a better educational background is more likely to be aware of immunization's importance. It is also possible that bettereducated mothers are more receptive to novelty and modern ideas, more confident in making decisions for their families' health, and more skilled at obtaining health information. Furthermore, preventive health services are more readily accepted by people with better educational backgrounds. Women with the most education are likely to be wealthier; they also have better access to health facilities and immunization services. Education is correlated with family welfare. Maternal education has also long been established as a significant predictor of childhood vaccination in India. Well-educated mothers have a positive relationship between immunization and maternal education [54]. Based on these findings, when there is a higher concentration of illiterate people in more deficient healthcare services settings, improving access to PHCs could help address inequities in vaccination coverage in areas characterized by lower maternal education levels. In our study, approximately half $(48.5 \%)$ of mothers were illiterate.

In our study, $204(49.3 \%)$ children born in government institutions, 174 (62.8\%) born in private institutions received all age-appropriate doses of immunization. Our finding that children born in government institutions were at greater risk of non-vaccination than those born in private institutions. Government institutions need to be further strengthened to deliver immunizations or increase immunization coverage. There is a need to provide financial or policy incentives for government facilities to ensure that children are appropriately immunized.

Another finding in the study was the poor knowledge of the caregivers regarding immunization. Though a clear majority of the 
respondents agreed that vaccination is essential to protect their children from deadly infectious diseases, most of them could not even name one condition that immunization protected against. This observation further cemented with the finding that the main reason for the failure of vaccination was a lack of knowledge about the universal immunization schedule. Previous studies had highlighted that India's existing health inequities are related to a lack of attention to social determinants of health, including education, employment, and the healthcare system's failure to deliver to those in need [55]. We have found significant disparities in vaccination coverage between the richest and poorest children and between the children of mothers with high education and low education, confirming findings in previous literature [56, 57, 58]. Inequities in vaccination coverage among social and religious groups in India were also clearly evident. Previous vaccination studies [59] that investigated the effects of religion on vaccination coverage dichotomized religion as Hindu and non-Hindu and found that non-Hindu religions have lower vaccination coverages. Similar findings were seen in the study [60], who concluded that though many parents were aware of the importance of vaccination in general, specific information on the importance of completing the schedule and knowledge on vaccine-preventable diseases other than poliomyelitis were limited.

The present study was conducted at the grassroots level in all the four blocks of Mewat district, which shows the factors like lack of awareness regarding benefits of immunization at the community level, fear of the side effects because of vaccines is some of the challenges which need to be addressed at primary care level to achieve full immunization coverage. Briefly, community preparedness can be assessed and compared between the blocks to identify high priority areas for different stakeholders.

Although, UIP vaccines have been offered free of cost to everyone by the government. The time and financial cost of reaching the health facilities can be an obstacle to the parents. Household income influences the likelihood that children receive full immunization. This result is like the results of many previous studies that show that children from wealthier families are more likely to be immunized than from poorer families [61, 62, 63].

Similar to previous research studies about the number of living children or parity status, our study also showed that mothers who had more than four children were less likely to immunize their children; many children in the family decreased the chance of children receiving full immunization. The mother might become busy fulfilling her children's need as the number of children in the family increase [64].

Children in rural areas had no significantly different probability of receiving full immunization than children in urban areas. The sources of information in the present study regarding immunization were mainly healthcare workers $703(87.9 \%)$. Similar results were found in a survey [37]. They concluded that Auxiliary Nurse Midwives (ANMs), paramedical workers, were the primary source of information regarding children's immunization. Similar findings were seen in a study [65] that the most used source of vaccine information was the health care provider, i.e. (91.7\%).

Decreasing in coverage rates was observed between the subsequent vaccine doses. The dropout rate observed in this study was exceeding the WHO acceptable dropout limits $(>10 \%)$.

The gender gap in immunization coverage has been shown to exist in all states of India. These studies showed that female children are significantly less likely to receive full immunization than their male counterparts. Similar results were observed $(\mathrm{AOR}=1.40,95 \%$ CI 1.03-1.90)) and p-value $<0.02$ in the present study. The reasons for under- and nonvaccination were multifactorial and complex. Educational status of parents, place of delivery of the child, lack of awareness of next vaccine due dose, and lack of knowledge about immunization schedule, long-distance to a health facility, big family size was identified as predictors of full immunization coverage in the study.

\section{Conclusion}

As mentioned earlier, despite the program being in operation for more than three decades, the immunization program has not only failed in achieving its target but lagging far behind the 
90\% coverage mark in the district. An unfortunate fact is that though a clear majority of the population recognized the importance of immunization, superficial knowledge of the immunization schedule and failure in motivating the target population for completing the immunization schedule has led to a large proportion of the children being partially immunized. Fear of AEFIs has also played a critical role in preventing children from getting vaccinated without proper communication to alleviate the concern by the health system.

The government should develop a comprehensive multi-pronged strategy to address vaccine hesitancy and bring out the observed changes in society's male members' attitudes and practices. These efforts should be directed in both directions. The demand side should raise the community awareness of the importance of timely completion of vaccination. From the supply side, the government should create effective communication strategies to address the fears regarding AEFIs among the community to participate in the vaccination program effectively.

Findings of our study call for a social mobilization programme which is required to prevent dropout from immunization, particularly by families of the girl children. The government and local administration must mobilize community and religious leaders to boost immunization rates and ensure equity in demand for immunization and access by children of both the genders. As a matter of policy, gender issues must be integrated into child immunization programme of the state, particularly in Mewat.

\section{Limitation}

The immunization history by mother's recall was a limitation. This is prone to systematic error (recall bias) caused by differences in accuracy of immunization information over a period up to 2 years, and most were uneducated. Since immunization status and predicting factors were assessed simultaneously, it is impossible to establish a cause-effect relationship. Despite this limitation, the results are useful for immunization program managers, the research community, and Haryana's government.

To improve immunization coverage, the Government of India has launched several programs. One of these is the Mission Indradhanush program, which provides immunization services closer to the community. Even though immunization coverage has been improving year by year in the country, it is still below the WHO standard of $80 \%$ in Mewat. This disparity might be elucidated by either household- or district-level determinants. Low maternal education levels, high poverty levels, and poor access to professional health attendants for maternal and child health services are among the district's characteristics with low immunization coverage. Mewat is having relatively few hospitals and health centers.

Our recommendations to the government could enhance the sub-health centers in the villages and ensure community empowerment. Improving health workers' communication skills can be key in imparting information about immunization to families and decision-makers. Improving mothers' and fathers' health knowledge by merely involving the community leaders would provide an approach to informing families about immunization, especially for fathers with lower formal education levels. Increasing the number of health workers (auxiliary nursing midwives) is essential for immunization coverage. The government should provide funding to increase the number of health workers at the village level. Improvement of health workers' quality has also proven an excellent policy to improve the quality of health. Finally, reducing economic inequality among all to ensure equitable coverage. 


\section{References}

[1] United Nations Inter-Agency Group for Child Mortality Estimation (UN IGME) United Nations Children's Fund; New York: 2017. Levels \& Trends in Child Mortality: Report 2017. Estimates Developed by the UN Inter-agency Group for Child Mortality Estimation.

[2] National, regional, and global levels and trends in neonatal mortality between 1990 and 2017, with scenario-based projections to 2030: a systematic analysis. Lucia Hug, Monica Alexander, Danzhen You, Leontine Alkema on behalf of the UN Interagency Group for Child Mortality Estimation. Published: June, 2019 DOI: https://doi.org/10.1016/S2214-109X(19)30163-9.

[3] https://www.who.int/immunization/monitoring_s urveillance/who-immuniz.pdf.

[4] https://www. who.int/teams/immunizationvaccines-and-biologicals/strategies/global-vaccineaction-plan.

[5] World Health Organization (WHO).2017.10 Facts on Immunization. retrieved from: http://www.who.int/features/factfiles/immunization/ en/.

[6] Gurnani V, Haldar P, Aggarwal MK, Das MK, Chauhan A, Murray J, et al. Improving vaccination coverage in India: Lessons from intensified mission Indra Dhanush, cross-sectoral systems strengthening strategy. BMJ. 2018;363: k4782.

[7] Ministry of Health and Family Welfare. Mission Indradhanush, operational guidelines. Delhi, India: MOHFW,

2014.

http://164.100.158.44/showfile.php?lid=4258.

[8] Ministry of Health and Family Welfare (MOHFW). Intensified Mission Indradhanush, operational guidelines. MOHFW, 2017.https://mohfw.gov.in/sites/default/files/Missio n\%20Indradhanush\%20Guidelines.pdf.

[9] International Institute for Population Sciences. District Level Household and Facility Survey-4: District Fact Sheet Mewat (2012-13). Mumbai: Ministry of Health and Family Welfare; 2012.

[10] International Institute for Population Sciences (IIPS) and ICF. National family health survey (NFHS-4), 2015-16: India. IIPS, 2017. https://dhsprogram.com/pubs/pdf/FR339/FR339.pdf. [11] https://nhm.gov.in/New_Updates_2018/NHM_ Components/Immunization/Guildelines_for_immuni zation/IMI_CES_Survey_Report.pdf.

[12] Immunization Division, Ministry of Health and Family Welfare, Government of India. (2019). Road Map for achieving $90 \%$ full immunization coverage
DOI: 10.21522/TIJPH.2013.09.01.Art019

in India, a guiding document for the states. MoHFW: New Delhi.

[13]Directorate of Census Operations Haryana. Census of India 2011 Haryana: Series-07: Part XIIB: District Census Handbook Mewat: Village and Town Wise Primary Census Abstract (PCA) [Internet]. Chandigarh: Ministry of Home Affairs, Government of India; 2011. http://censusindia.gov.in/2011census/dchb/0619_PA RT_B_DCHB_MEWAT.pdf.

[14]Philip, Rachel. 2017.Breaking Barriers: The Status of Adolescent Girls' Education in Mewat, Haryana. Doi. 10.13140/RG.2.2.30113.56160.

[15]Lwanga SK, Lamshhow S. Sample Determination in Health Studies; A Practical Manual. Geneva: World Health Organization; 1991. [16]Prinja S, Monga D, Rana SK, Sharma A, Dalpath S, Bahuguna P, Gupta R, Aggarwal AK. District-Level Analysis of Routine Immunization in Haryana State: Implications for Mission Indradhanush under Universal Immunization Programme. Indian J Community Med. 2018 JulSep;43(3):209-214. doi: 10.4103/ijcm.IJCM_306_17. PMID: 30294090; PMCID: PMC6166503.

[17] Angadi MM, Jose AP, Udgiri R, Masali KA, Sorganvi V. A Study of Knowledge, Attitude and Practices on Immunization of Children in Urban Slums of Bijapur City, Karnataka, India. Journal of Clinical and Diagnostic Research. 2013;7(12): 28036.

[18]WHO. Immunization Coverage [Internet]. World Heal. Organ. Fact Sheet Immun. Cover. 2016. [cited 2017 Mar 6]. Available from: http://www.who.int/mediacentre/factsheets/fs378/en. [19] Nair TN, Varughese E (1994) Immunization coverage of infants - the rural-urban difference in Kerala. Indian Pediatrics 31:139-143.

[20] Agarwal S, Bhanot A, Goindi G (2005) Understanding and addressing childhood immunization coverage in urban slums. Indian Pediatrics 42: 653-663.

[21]Desai S, Alva S (1998) Maternal education and child health: Is there a strong causal relationship? Demography 35 1: 71-81.

[22] UNICEF (2009) Coverage Evaluation Survey. Government of India, Ministry of Health and Family Welfare and UNIC EF. Available: www.unicef.org/india/health_5578.htm and www.unicef.org/india/National_Fact_Sheet_CES_2 009.pdf.

[23] Gaudin S, Yazbeck AS (2006) Immunization in India 1993-1999: Wealth, gender, and regional 
inequalities revisited. Social Science and Medicine 62: 694-706.

[24] Mohanty SK, Pathak PK (2009) Rich-poor gap in utilization of reproductive and child health care services in India, 1992-2005. Journal of Biosocial Sciences 41 3: 381-398.

[25] Arokiasamy P, Pradhan J (2011) Measuring wealth-based health inequality among Indian children: the importance of equity vs. efficiency. Health Policy and Planning 26: 429-440.

[26]Dalal A, Silveira MP (2005) Immunization status of children in Goa. Indian Paediatrics 42: 401-402.

[27] Kumar A, Mohanty SK (2011) Socioeconomic differentials in childhood immunization in India, 1992-2006. Journal of Population Research 28 4: 301-324.

[28] Pande R (2003) Selective Gender differences in childhood nutrition and immunization in rural India: The role of siblings. Demography 40: 395-418.

[29] Corsi DJ, Bassani DG, Kumar R, Awasthi S, Jotkar R, et al. (2009) Gender inequity and ageappropriate immunization coverage in India from 1992 to 2006. BMC International Health Human Rights 14 Suppl. 1: S3-9.

[30] Singh P, Yadav RJ (2000) Immunization status of children of India. Indian Pediatrics 37: 1194 1199.

[31]Phukan RK, Barman MP, Mahanta J (2009) Factors associated with immunization coverage of children in Assam, India: over the first year of life. Journal of Tropical Pediatrics 55: 249-252.

[32] Babirye JN, Engebretsen IMS, Makumbi F, Fadnes LT, Wamani H, Tylleskar T, et al. timeliness of childhood vaccinations in Kampala Uganda: a community-based cross-sectional study. PLoS One. 2012; 7:1-6. 24.

[33]Etana B, Deressa W, Angela G, Zulfiqar B, Lulu B, Aly G, et al. Factors associated with complete immunization coverage in children aged 12-23 months in ambo Woreda, Central Ethiopia. BMC Public Health. 2012; 12:566. 25.

[34] Reynolds HW, Wong EL, Tucker H. Adolescents' use of maternal and child health services in developing countries. Int Fam Plan Perspect. 2006; 32:6-16.

[35] Nath L, Kaur P, Tripathi S. Evaluation of the universal immunization program and challenges in coverage of migrant children in Haridwar, Uttarakhand, India. Indian J Community Med [Internet] [cited 2020 Nov 10]. Available from: http://www.ijcm.org.in/article.asp?issn=0970-
0218; year $=2015 ;$ volume $=40 ;$ issue $=4$; spage $=239$; epa ge $=245$; aulast $=$ Nath .

[36] Vohra. Immunization coverage and its determinants among 12-23 months old children of Lucknow [Internet] [cited 2020 Nov 10]. Available from: http://www.mjmsr.net/article.asp?issn=09759727; year $=2013$; volume $=4 ;$ issue $=2 ;$ spage $=90$; epage $=95$; aulast $=$ Vohra.

[37] Nath B, Singh JV, Awasthi S, Bhushan V, Kumar V, Singh SK. A study on determinants of immunization coverage among 12-23 months old children in urban slums of Lucknow district, India. Indian J Med Sci. 2007; 61:598-606.

[38] Madhavi N, Manikyamba D. Evaluation of immunization status and factors responsible for dropouts in primary immunization in children between 1-2 years - A hospital-based study. Pediatr Rev Int J Pediatr Res. 2016; 3:332. Available from: http://medresearch.in/index.php/IJPR/article/view/74 7.

[39] Singhal G, Mathur H, Dixit M, Khandelwal A. Factors affecting immunization among children of the rural population of block Malpura, district Tonk, Rajasthan, India. Int J Community Med Public Health. 2016; 3:641-6.

[40]Kumar D, Aggarwal A, Gomber S. Immunization status of children admitted to a tertiary-care hospital of North India: Reasons for partial immunization or non-immunization. J Health, Popul Nutr. 2010;28(3):300-4.

[41] Kumar A, George K, Bose A. Immunization coverage among children aged 12-23 months in Surajgarha Block, Lakhisarai District, Bihar: A cluster sampling survey. National J Community Med. 2018; 9:5.

[42] Ahmad J, Khan ME, Hazra A. Increasing complete immunization in rural Uttar Pradesh. J Fam Welf. 2010; 56:65-72.

[43] Datta A, Baidya S, Datta S, Mog C, Das S. A study to find out the full immunization coverage of 12- to 23-month-old children and areas of underperformance using LQAS technique in a Rural Area of Tripura. J Clin Diagn Res JCDR. 2017;11:LC014.

[44] Murhekar MV, Kamaraj P, Kanagasabai K, Elavarasu G, Rajasekar TD, Boopathi K, et al. Coverage of childhood vaccination among children aged 12-23 months, Tamil Nadu, 2015, India. Indian J Med Res. 2017; 145:377.

[45] Khargekar NC, Khargekar VC, Shingade PP. Immunization status of children under 5 years in a Tribal Area, Parol, Thane District. Natl J Community Med. 2015; 6:522-7. 
[46] Kadri AM, Singh A, Jain S, Mahajan RG, Trivedi A. Study on immunization coverage in urban slums of Ahmedabad City. Indian J Public Health Res Dev. 2010; 33:5.

[47]Prusty RK, Kumar A (2014) Socioeconomic Dynamics of Gender Disparity in Childhood Immunization in India, 1992-2006. PLoS ONE 9(8): e104598. doi: 10.1371/journal.pone.0104598.

[48] Parpiev Z, Yusupov K (2009) Intrahousehold gender-based discrimination among children in Uzbekistan. Working paper, No 09/10E. Economics Education and Research Consortium.

[49] Nasir R, Kalla AK (2006) Kinship system, fertility, and son preferences among the Muslims: A review. Anthropologist 8 4: 275-281.

[50] Pande R, Astone NM (2007) Explaining son preference in rural India: The independent role of structural versus individual factors. Population Research and Policy Review 26(1):1-29.

[51] Partha D, Bhattacharya BN. Determinants of child immunization in four less-developed states of north India. J Child Health Care. 2002 Mar;6(1):3450. doi: 10.1177/136749350200600105. PMID: 12036175 .

[52]Rammohan A, Awofeso N, Fernandez RC. Paternal education status significantly influences infants' measles vaccination uptake, independent of maternal education status. BMC Public Health. 2012;12(1):336. （http://dx.doi.org/10.1186/14712458-12-336).

[53] Mathew JL. Inequity in childhood immunization in India: a systematic review. Indian Pediatr. 2012;49(3):203-223. http://dx.doi.org/10.1007/s13312-012-0063-z. [54] Vikram K., Vanneman R., Desai S. Linkages between maternal education and childhood immunization in India. Soc. Sci. Med. 2012; 75:331-339. doi: 10.1016/j.socscimed.2012.02.043. [55]P.K. Singh, C. Kumar, R.K. Rai, L. Singh. Factors associated with maternal healthcare services utilization in nine high focus states in India: a multilevel analysis based on 14385 communities in 292 districts. Health Policy Plan, 29 (5) (2014), pp. 542-559. (http://dx.doi.org/10.1093/heapol/czt039). [56]Kumar A, Mohanty SK. Socioeconomic differentials in childhood immunization in India,
1992-2006. J Popul Res. 2011;28(4):301-324. (http://dx.doi.org/10.1007/s12546-011-9069-y).

[57] Joe W, Mishra US, Navaneetham K. Socioeconomic inequalities in child health: recent evidence from India. Glob Public Health. 2010;5 (5):493-508. (http://dx.doi.org/10.1080/17441690903213774). [58] Fernandez R, Rammohan A, Awofeso N. Correlates of the first dose of measles vaccination delivery and uptake in Indonesia. Asian Pac J Trop Med. 2011; 4:140-5. 14.

[59] Gatchell M, Thind A, Hagigi F. Informing statelevel health policy in India: the case of childhood immunizations in Maharashtra and Bihar. Acta Paediatr. 2008;97(1):124-126.

(http://dx.doi.org/10.1111/j.1651-

2227.2007.00569.x)

[60] Manjunath U, Pareek RP. Maternal knowledge and perceptions about the routine immunization program. A study in a semi-urban area in Rajasthan. India J Med Sci. 2003; 57:158-63.

[61] Mbengue MAS, Sarr M, Faye A, Badiane O, Camara FBN, Mboup S, et al. Determinants of complete immunization among Senegalese children aged 12-23 months: evidence from the demographic and health survey. BMC Public Health. 2017; 17:630. 39.

[62] Lakew Y, Bekele A, Biadgilign S. Factors influencing full immunization coverage among 1223 months of age children in Ethiopia: evidence from the national demographic and health survey in 2011. BMC Public Health. 2015; 15:728. 40.

[63] Adedokun ST, Uthman OA, Adekanmbi VT, Wiysonge CS. Incomplete childhood immunization in Nigeria: a multilevel analysis of individual and contextual factors. BMC Public Health. 2017; 17:236.

[64] Sia D, Fournier P, Kobiané J-F, Sondo BK. Rates of coverage and determinants of complete vaccination of children in rural areas of Burkina Faso (1998-2003). BMC Public Health. 2009; 9:416. [65] Abbey M. Jones, Saad B. Omer, Rober A. Bednarczyk, Neal A. Halsey, Lawrence H. Moulton, and Daniel A. Salmon. Advances in Preventive Medicine. Volume 2012, Article ID 932741. Doi:10.1155/2012/932741. 